\title{
Studies on the possible application of heat storage devices for powering the ORC (Organic Rankine Cycle) systems
}

\author{
Piotr Kolasiński ${ }^{1, *}$ \\ ${ }^{1}$ Wrocław University of Science and Technology, Department of Thermodynamics, Theory \\ of Machines and Thermal Systems, Wybrzeże Wyspiańskiego 27, 50-370 Wrocław, Poland
}

\begin{abstract}
Some of the heat sources (such as e.g. waste or renewable), are characterized by floating thermal and output characteristics. Thus, their application for powering vapor power plants, such as ORCs, which should utilize the heat sources having steady thermal and output characteristics is difficult. The floating heat source characteristics may potentially be improved using the heat storage devices providing the thermal energy accumulation at stable output and temperature level. Heat storage device can be adopted as a e.g. steady-level heat source for ORC system. In this paper different applications of the heat storage devices in ORCs were proposed and the results of experiments on powering the ORC system via heat storage device are presented. The results showed that adopting the heat storage devices for powering the ORC systems is possible and it is a promising way of utilizing the waste and renewable heat sources featuring floating characteristics.
\end{abstract}

\section{Introduction}

One of the problems connected with the use of the selected renewable and waste heat sources is their periodic appearance and floating characteristics of the heat source power, heat carrying medium output and temperature. This applies to renewable as well as waste resources. For example the appearance of solar radiation and some geothermal sources (e.g. geysers) is changing in time. The appearance of the industrial waste heat sources, depends mainly on type of technological processes in which these heat is released, its characteristic and dynamics. An exemplary floating thermal characteristic of the waste heat source is presented in Fig. 1. Floating characteristics of the heat source including its power, output and heat carrying medium temperature causes difficulties in their usage. Therefore, they must be utilized directly at the time of their appearance. It is worth to note that in the case of industrial processes the characteristics of the waste heat release and demand for heat in the process not always matches (it is also true when heat from renewable energy sources is considered). Therefore, the issues related to the recovery of this heat and the design of energy systems utilizing such heat sources are complex. What is more, these energy systems have to adapt to changing conditions of the heat supply.

\footnotetext{
*Corresponding author: piotr.kolasinski@pwr.edu.pl
} 


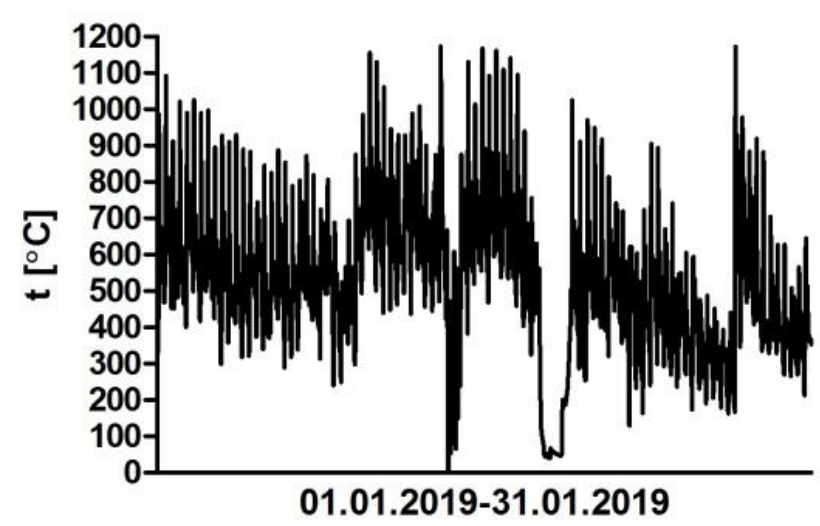

Fig. 1. Exemplary floating thermal characteristic of the waste heat source

Often, alternative heat sources with floating characteristics are low-quality (i.e. they are featuring low power, low temperature and low output of heat carrying medium). The most promising way of application of this low-quality heat is the conversion to high-quality energy products (such as electricity, heat or cold). The multigeneration or cogeneration steam power plants, or vapour power systems (such as e.g. Kalina or ORC systems) can be applied for this purpose. However, in terms of the operating conditions of vapour power systems the direct application of the heat sources featuring floating thermal and output characteristics for their powering may be difficult. In classical steam power plants, and selected ORCs the heat is supplied by a boiler (which can be fed by different fuels, including alternative fuels such as biomass, biogas, etc.). In the case of Kalina systems and ORCs heat may also be supplied to the system from alternative sources (such as, e.g., high temperature solar or geothermal heat). During the normal operation of these systems the heat source characteristics are steady, which translates into steady operating conditions of the power plant. In the case of the heat sources featuring floating characteristics of the heat supply the power plant operates under floating conditions. The thermal properties (pressure and temperature) of steam or vapour which is generated in a systems' steam generator may in this case vary which directly translates to floating operating conditions of the systems' expander. Turbines are usually designed for fixed values of the working fluid flow and its thermal parameters and floating operating conditions are disadvantageous from the point of view of turbine life and durability. If the quality of the working fluid vapour at the turbine inlet is low (which can be caused by variable conditions of the heat supply), there is a risk of condensation of liquid particles during the expansion, which may result in erosion of the turbine blades. In the case of volumetric expanders, the risk of expander damage resulting from variable conditions of the heat supply is lower than in the case of turbines. Nevertheless, there is a need for special design of the power systems which are powered by the heat sources featuring floating characteristics. There is also a need of continuous control of the system in order to provide its adaptability to changing heat supply conditions. A possible way of improving the applicability of a heat sources featuring floating characteristics for powering the power plants may be their combination with heat storage systems (HSS). Technologies related to heat storage are up-to-date and thus they are intensively investigated in many scientific and development units. Such systems are used in the industry for storing heat, however, according to the authors' knowledge, these systems are not yet practically applied for powering power systems. In the following part of the article, a description of modern heat storage systems and 
analysis of various ways of their application in vapour power plants (with special attention paid to ORC systems) is presented.

\section{Heat storage devices and systems}

The main purpose of the heat storage systems application is a short or a long-term heat storage. The heat storage system can be charged by different heat sources (i.e., conventional as well as renewable and waste sources). The main component of the heat storage system is the heat storage device (HSD). Depending on the type of the heat storage device used, the heat can be stored for various time periods, starting from a short-term (few hours) to a long-term periods (several months). In terms of the design, type of the applied heat storage substance and operating principle, heat storage devices can significantly differ. The basic features of heat storage devices are its capacity, power, efficiency, storage period, charge and discharge time and costs [1]. The heat storage device should feature high power density (compact dimensions), simple design and high reliability [2]. It should also be easy to transport and assembly and fully automated. By the physical phenomenon being the principle of heat storage device operation and the type of heat storage substance used, heat storage devices can be classified into the types listed in Table 1 [1].

Table 1. Classification of heat storage devices by the physical phenomenon being the principle of heat storage device operation [1].

\begin{tabular}{|c|c|c|}
\hline Phenomena & Heat type & Medium \\
\hline \multirow{4}{*}{ Thermal phenomena } & Sensible heat & Liquids \\
\cline { 2 - 3 } & & Solids \\
\cline { 2 - 3 } & \multirow{3}{*}{ Latent heat } & Solid-liquid \\
\cline { 2 - 3 } & & Liquid-gas \\
\cline { 2 - 3 } Chemical phenomena & Thermal chemical pipe line & Solid-solid \\
\cline { 2 - 3 } & Heat of chemical reaction & - \\
\cline { 2 - 3 } & Chemical heat pumps & - \\
\hline
\end{tabular}

In this study the author limited the analysis to these heat storage devices which principle of operation is based on thermal phenomena. The heat storage substance which is used in these heat storage devices should feature high values of thermal capacity and specific heat. It should also be chemically stable and resistant to cyclic changes in the thermal load resulting from the cyclic processes of charging and discharging. The applied solids are e.g. rocks (granite or steatite), reinforced concrete, cast iron, cast steel as well as silica and magnesia fire bricks [1]. The applied liquids are water, organic fluids and different types of oil (including hardening oils) [1]. The applied phase change materials (PCMs) are organic, inorganic and eutectic substances, such as hydrated salts, paraffin, etc. [1]. When PCMs are applied as heat storage substances, the heat storage device efficiency increases due to the beneficial effect of latent heat release during the phase transition.

The basic technical parameters (i.e. the operating temperature range, capacity, power, efficiency, storage period and cost) of the heat storage device depend on the device type and the type of heat storage substance used. The typical parameters of the heat storage devices are listed in Table 2 [1]. The operating temperature of the heat storage devices varies in the range of $200-1200^{\circ} \mathrm{C}$ (in the case of solid heat storage substances), $20-260^{\circ} \mathrm{C}$ (in the case of liquids) and $20-120^{\circ} \mathrm{C}$ (in the case of PCMs) [1]. The design and operating principle of the 
heat storage devices which are applied in the industry is similar to classic shell-and-tube heat exchangers. However, the difference is that the heat from the heat carrier is transferred to the heat storage substance instead of the second working fluid. Heat which is stored in the heat storage device can be used for different purposes (e.g. as technological heat). One of the examples of the heat storage system application in the industry can be found in Siekierki CHP Plant (Warsaw, Poland) [3]. The heat stored in this storage system can be used to cover the own needs of the power plant as well as by the external customers. The other example is the heat storage system based on PCMs and used for central heating. This system was successfully applied in the Court Centre in Düsseldorf [4].

Table 2. Typical parameters of heat storage devices [1].

\begin{tabular}{|c|c|c|c|c|c|}
\hline Type of device & Capacity (kWh/t) & $\begin{array}{c}\text { Power } \\
(\mathbf{M W})\end{array}$ & $\begin{array}{c}\text { Efficiency } \\
(\mathbf{\%})\end{array}$ & $\begin{array}{c}\text { Storage } \\
\text { period }\end{array}$ & $\begin{array}{c}\text { Cost } \\
(\mathbf{E U R} / \mathbf{k W})\end{array}$ \\
\hline $\begin{array}{c}\text { Sensible (hot } \\
\text { water) }\end{array}$ & $10-50$ & $0.001-10.0$ & $50-90$ & Days/months & $0.1-10$ \\
\hline $\begin{array}{c}\text { Phase-change } \\
\text { material (PCM) }\end{array}$ & $50-150$ & $0.001-1.0$ & $75-90$ & Hours/months & $10-50$ \\
\hline $\begin{array}{c}\text { Chemical } \\
\text { reactions }\end{array}$ & $120-250$ & $0.01-1.0$ & $75-100$ & Hours/days & $8-100$ \\
\hline
\end{tabular}

\section{Possible applications of the heat storage systems in ORCs}

The ORC systems can be classified according to different criteria $[5,6]$. By temperature of the heat source carrier, they can be classified into systems powered by high- (more than $\left.500^{\circ} \mathrm{C}\right)$, medium $-\left(250-500^{\circ} \mathrm{C}\right)$, and low- $\left(40-250^{\circ} \mathrm{C}\right)$ temperature heat sources. The heat can be delivered to the system from renewable or waste sources. By power, ORCs can be classified into systems featuring high power (500 kW or more), medium power $(100-500 \mathrm{~kW})$, small power $(10-100 \mathrm{~kW})$ and micro power $(0.5-10 \mathrm{~kW})$, whereby the higher powers apply to systems supplied from sources with higher thermal parameters. By the type of the applied expander, ORCs can be classified into systems adopting turbines or systems adopting volumetric expanders. Comprehensively the ORC system design and operating principle are described in $[5,6]$. ORC systems are applied to harvest heat from renewable heat sources (i.e. solar energy, geothermal heat, heat obtained from biomass or biogas combustion) and waste heat sources (appearing in various industries, i.e. energy, chemical, food, metallurgy, cement, glass and others). Systems that are supplied by heat obtained from the renewable fuels (i.e. biomass and biogas) combustion will not be considered in the current study, as these heat sources feature steady thermal and output characteristics. In Table 3 [7], the temperature ranges of various renewable and waste heat sources applied for ORC systems powering have been summarized.

The comparison of the above described ORC system classification with the temperature ranges of various renewable and waste heat sources and the operating temperatures of different types of heat storage devices shows that heat storage devices utilizing solids (with operating temperature range of $200-1200{ }^{\circ} \mathrm{C}$ ) and liquids (with operating temperature up to ca. $260^{\circ} \mathrm{C}$ ) as a heat storage substances are the most promising for combination with ORC systems. The application of heat storage devices using PCMs in ORCs can be limited due to the low range of operating temperature (up to ca. $120^{\circ} \mathrm{C}$ ).

The different applications of the heat storage devices in ORCs can be considered. They can be applied e.g. in order to provide a standby heat source, improve the ORC system efficiency, pre-heat of the working fluid and other purposes. Fig. 2 shows the proposed configurations of ORC systems combined with the heat storage devices. 
The efficiency of basic ORC system powered by the heat storage device (see, Fig. 2a) can be described by the equation

$$
\eta=N_{\mathrm{ORC}} /\left(Q^{+} \mathrm{HSS}\right)
$$

where $N_{\mathrm{ORC}}$ is the power of the expander, $Q^{+}{ }_{\text {HSS }}$ is the heat transferred to the working medium of the ORC system in the HSS.

Table 3. The temperature ranges of selected renewable and waste heat sources applied for ORC systems powering [7].

\begin{tabular}{|c|c|c|}
\hline Renewable source/industrial process & Heat carriers & Temperature range $\left({ }^{\circ} \mathbf{C}\right)$ \\
\hline Solar heat & - & $50-400$ \\
\hline \multirow{2}{*}{ Geothermal heat } & Water & $30-80$ \\
\cline { 2 - 3 } & Steam & $110-120$ \\
\hline \multirow{3}{*}{ Power plant } & Exhaust gases & $250-1200$ \\
\cline { 2 - 3 } & Cooling mediums & $40-150$ \\
\cline { 2 - 3 } & Solid and liquid waste & $40-200$ \\
\cline { 2 - 3 } & Waste steam & $150-300$ \\
\cline { 2 - 3 } & Hot elements & $40-400$ \\
\hline \multirow{3}{*}{ Chemical plant } & Process gases & $100-600$ \\
\cline { 2 - 3 } & Liquids & $40-200$ \\
\cline { 2 - 3 } & Hot elements & $40-300$ \\
\hline \multirow{3}{*}{ Food processing plant } & Liquids & $40-100$ \\
\cline { 2 - 3 } & Cooling air & $50-100$ \\
\cline { 2 - 3 } & Hot elements & $40-400$ \\
\hline \multirow{3}{*}{ Metal processing industry } & Exhaust gases & $250-1200$ \\
\cline { 2 - 3 } (Steel-mills, Copper smelters, etc.) & Process gases & $300-1400$ \\
\cline { 2 - 3 } & Cooling mediums & $40-150$ \\
\cline { 2 - 3 } & Solid and liquid waste & $40-200$ \\
\cline { 2 - 3 } & Hot elements & $40-700$ \\
\hline Class manufacturing & Flue gases & $340-380$ \\
\hline \multirow{3}{*}{ Cement industry } & Flue gases & $400-500$ \\
\hline
\end{tabular}

The efficiency of the ORC system in which the heat storage device is used for interstage heating of the working medium or direct feeding the second stage of the expander (see Fig. 2f) can be described by the equation:

$$
\eta=\left(N_{\mathrm{ORC} 1}+N_{\mathrm{ORC} 2}\right) /\left(Q^{+} \mathrm{ORC}^{+} Q^{+}{ }_{\mathrm{HSS}}\right)
$$

where $N_{\mathrm{ORC} 1}$ is the power of the first stage of the expander, $N_{\mathrm{ORC} 2}$ is the power of the second stage of the expander, $Q^{+}$ORC is the heat transferred to the working medium of the ORC system in the evaporator, $Q^{+} \mathrm{HSS}$ is the heat transferred to the working medium of the ORC system in the HSS.

As can be seen from this equation, the application of heat storage device for interstage heating of the working medium or direct feeding the second stage of the expander may result in the increased power of the expander and thus, the system efficiency. The equations that 
can be used for calculating the efficiency of the systems presented in Figs. $2 b-2 e$ were presented in [2].

a)

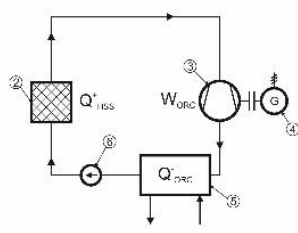

d)

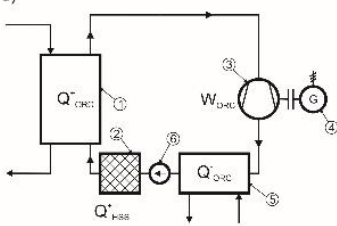

b)
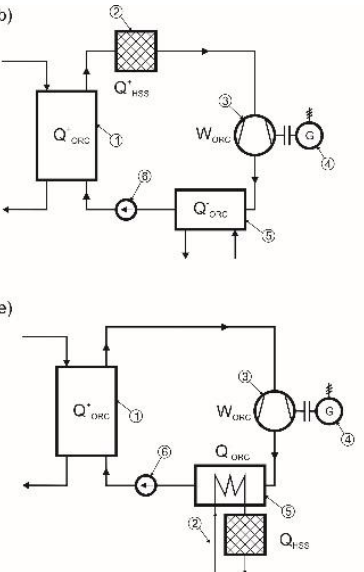

c)
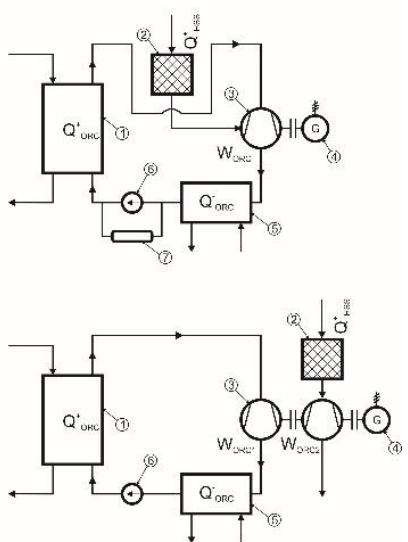

Fig. 2. Proposed configurations of ORC systems combined with the heat storage devices 1 - vapour generator; 2 - heat storage device/HSS; 3 - expander; 4 - generator; 5 - condenser; 6 - feeding pump; 7 - working fluid reservoir

a) HSS used for powering the ORC system, b) HSS used for stabilizing the floating thermal and output characteristics of the heat source and improving the conditions of the heat supply to the ORC system evaporator, c) HSS used for providing the additional feeding of the expander with the working fluid, d) HSS used for pre-heating of the working fluid, e) HSS used for CHP, f) HSS used for interstage heating of the working fluid or direct feeding the second stage of the expander.

\section{Results of preliminary experiment on powering ORC system by heat storage device}

The experimental investigations were carried out using a prototype of combined heat and power (CHP) ORC system adopting multi-vane expander. The design and operating principle of this test-system was comprehensively described in $[5,6]$. The heat source for this experimental system is hot water provided by the gas central heating boiler. The hot water circulates in the loop formed by the boiler and the shell of the shell-and-tube evaporator. The evaporator features the thermal power of $6 \mathrm{~kW}$, the volume of the pipes of 6.6 liters and the volume of the shell of 20.8 liters. In order to maximally limit the heat losses the evaporator is insulated with a layer of glass wool ( $5 \mathrm{~cm}$ thick). If the valves at the inlet and at the outlet of the evaporator are closed, heated water is closed in the shell of the evaporator and thus, the evaporator can be treated as a heat storage device.

The main aim of the experiment is the analysis of variation of ORC system operating conditions during its powering via the heat storage device. The experimental series were carried out for the following settings of the water temperature: $45^{\circ} \mathrm{C}, 55^{\circ} \mathrm{C}, 75^{\circ} \mathrm{C}$ and $85^{\circ} \mathrm{C}$. When the water temperature reached the set value, the boiler was switched off and the inlet and the outlet valve of the evaporator were closed. Then, the working fluid pump was started and the liquid working fluid (R123) was flowing through the coil of the evaporator. During all experiments, the flow of low-boiling working fluid was maintained at a constant level of $150 \mathrm{l} / \mathrm{h}$. The experiment consisted of measuring the heat storage device discharge time. During experiments test-stand operational parameters, i.e., the flow rate of the R123, pressure and temperature of R123 at the outlet of the exchanger and at the expanders' inlet and outlet were recorded. The experiments were finished when the temperature of the 
working fluid at the outlet of the exchanger stabilized and there was no heat exchange observed between the heat storage medium and low-boiling working fluid.

Figure 3 a shows the variation of the working fluid pressure at the inlet of the expander during the experiment for different values of the water temperature $\left(t_{w}\right)$, while Figure $3 \mathrm{~b}$ shows these selected experimental results for which the working fluid pressure at the inlet of the expander was higher or equal to 1.5 bar (i.e., the minimum pressure needed for driving the expander).

a)

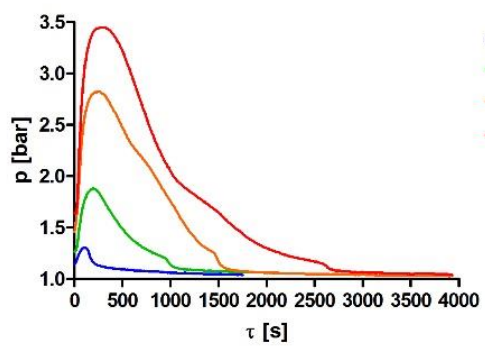

b)

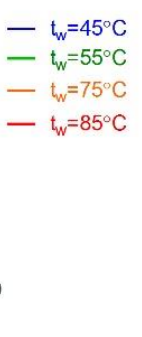

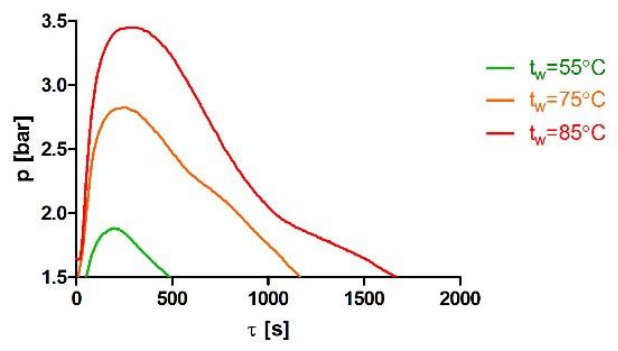

Fig. 3. The variation of the working fluid pressure at the inlet of the expander during the experiment duration, a) full experimental results, b) selected experimental results (limited to the pressure of 1.5 bar).

The analysis of the experimental results presented in Figure 3a, is crucial for the recognition of the applicability of the heat storage devices for ORC systems powering. In the experimental ORC system a volumetric expander, i.e., a multi-vane machine, was adopted. This type of expander features a small need for working medium flow but requires a certain level of working fluid pressure at the inlet which is necessary to drive the rotor. As it was proved in previous studies $[8,9]$, the working fluid pressure at the inlet to the tested expander have to be higher than 1.5 bar. For lower values of pressure at the expanders' inlet, it was not possible to put the expanders' rotor in motion. Moreover, this expander features an optimum expansion ratio (i.e., the ratio of the pressure on the expanders' inlet to the pressure on the expanders' outlet) ranging from 3.5 up to 4.5. As can be seen from Figure 3a, maintaining the required working fluid pressure at the expander inlet was not possible in selected investigated cases, i.e., the minimum working fluid inlet pressure was not reached in case of heat storage medium temperature of $45^{\circ} \mathrm{C}$ (blue line). Thus, it was not possible to put the expander into operation during this experimental series. In other experimental series a minimum pressure at the inlet to the expander was obtained only during limited time of the experiment duration. As can be seen from Figure 3b during the experiment in which

- the initial heat storage medium temperature was equal to $55^{\circ} \mathrm{C}$ (green line) the maximum pressure at the inlet to the expander (equal to 1.9 bar) was obtained in $3^{\text {rd }}$ minute of the experiment duration. In this experimental series, the pressure higher than 1.5 bar was maintained for ca. 8 minutes.

- the initial heat storage medium temperature was equal to $75^{\circ} \mathrm{C}$ the maximum pressure at the inlet to the expander (equal to 2.8 bar) was obtained in 4th minute of the experiment duration and the pressure higher than 1.5 bar was maintained for ca. 19 minutes.

- the initial heat storage medium temperature was equal to $85^{\circ} \mathrm{C}$. The maximum pressure at the inlet to the expander (equal to 3.4 bar) was obtained in 4th minute of the experiment duration and the pressure higher than 1.5 bar was maintained for ca. 27 minutes. 
The experimental results proved that it is possible to power the ORC system adopting volumetric expander from the heat storage device. Depending on the thermal parameters of the heat storage medium, the operating time of the ORC system and its performance varies.

\section{Summary and conclusions}

This paper presents the concept and the results of preliminary experimental analysis on possible application of the heat storage devices in ORC systems. Heat storage devices are especially promising for powering the ORC systems utilizing the heat sources with floating output and temperature characteristics, such as, e.g. waste or solar heat. Different configurations of the heat storage devices and ORCs were proposed in this paper. The experiment on powering the ORC system via heat storage device under variable heat storage medium temperatures was conducted. During the experiments different temperature levels of heat storage medium were analysed. Depending on the temperature of the heat storage medium, different operating times of the ORC system and different thermodynamic parameters of low-boiling working fluid were obtained. The experimental results proved that it is possible to drive the ORC system via heat storage device if the heat storage medium features such temperature, which is needed for low-boiling working fluid heating, evaporation and obtaining the vapour pressure at the level needed to drive the expander. The system operating time ranged between 8 and 27 minutes depending on the heat storage medium temperature.

The experiments were performed on a very small device in a limited range of experimental conditions. However, the experimental aim was achieved and the results are representative also for larger vapour power systems adopting volumetric expanders.

Encouraged by the obtained results, the author decided to continue the research on the application of heat storage devices in ORC systems.

\section{References}

1. I. Sarbu, C. Sebarchievici, Sustainability 10, 191 (2018)

2. P. Kolasiński, Przegląd Elektrotechniczny 7, 227-279 (2013)

3. P. Kuczia, Instal 3, 2-5 (2012)

4. W. Bujalski, Rynek Energii 4, 131-136 (2012)

5. Z. Gnutek, P. Kolasiński, J. Eng. Gas Turb. Power Journal 135, 061901 (2013)

6. P. Kolasiński, Energies 8, 3351-3369 (2015)

7. E. Kolasińska, P. Kolasiński, Materials 9, 485 (2016)

8. P. Kolasiński, P. Błasiak, J. Rak, Energies 9, 606 (2016)

9. J. Rak, P. Błasiak, P. Kolasiński, Energies 11, 892 (2018) 